\title{
O PERFIL DO ALUNO EGRESSO NO CURSO DE ADMINISTRAÇÃO NA MODALIDADE DE EDUCAÇÃO A DISTÂNCIA E SUAS PERCEPÇÕES DE QUALIDADE - UMA REALIDADE DE UMA INSTITUIÇÃO PRIVADA DO RIO GRANDE DO SUL/BRASIL
}

\author{
PERFIL DEL EGRESO EN EL CURSO DE ADMINISTRACIÓN EN EL MODO DE \\ EDUCACIÓN A DISTANCIA Y SUS PERCEPCIONES DE CALIDAD - UNA \\ REALIDAD DE UNA INSTITUCIÓN PRIVADA DEL RÍO GRANDE DO SUL/ BRASIL
PROFILE OF THE EGRESS STUDENT IN THE ADMINISTRATION COURSE IN THE DISTANCE EDUCATION MODE AND ITS PERCEPTIONS OF QUALITY - A \\ REALITY OF A PRIVATE INSTITUTION OF RIO GRANDE DO SUL/BRASIL
}

RESUMO: O presente estudo pretende conhecer o perfil acadêmico do estudante egresso no curso de Administração na modalidade de ensino a distância e suas percepções de qualidade, mediante um estudo de caso na de uma Instituição de Ensino Superior (IES) privada no estado do RS. A realização da pesquisa deu-se na turma do curso de Administração EaD egressos do ano de 2015. Trata-se uma pesquisa exploratória, quantitativa, e para coleta dos dados foi aplicado um questionário mediante uma amostragem não probabilística, por conveniência, e foram pesquisados um total de 35 alunos egressos 2015. A análise dos dados foi feita com o auxílio do software estatístico Gretl. Os principais resultados obtidos revelam que a maioria dos alunos (61\%) é do sexo feminino, que somente $2 \%$ dos pesquisados não tem nenhuma forma de trabalho e se considera somente estudante, que $38 \%$ dos entrevistados conseguiram de alguma forma melhorar sua condição profissional com o curso em análise e ainda $78 \%$ escolheu a modalidade $\mathrm{EaD}$ em função da flexibilidade de horário e que $80 \%$ recomendaria o curso para um amigo.

PALAVRAS-CHAVE: Egressos. Administração. EAD. Qualidade.

RESUMEN: El presente estudio pretende conocer el perfil académico del estudiante egresado en el curso de Administración en la modalidad de enseñanza a distancia y sus percepciones de calidad, mediante un estudio de caso en la de una Institución de Enseñanza Superior (IES) privada en el estado de RS. La realización de la investigación se dio en la clase del curso de Administración EaD egresados del año 2015. Se trata de una investigación exploratoria, cuantitativa, y para la recolección de los datos se aplicó un cuestionario mediante un muestreo no probabilístico por conveniencia y se investigó un total de 35 alumnos egresados 2015. El análisis de los datos fue realizado con el auxilio del software estadístico Gretl. Los principales resultados obtenidos revelan que la mayoría de los alumnos (61\%) es del sexo femenino, que sólo el $2 \%$ de los encuestados no tiene ninguna forma de trabajo y se considera solamente estudiante, que el $38 \%$ de los entrevistados consiguió de

${ }^{1}$ Instituto Federal de Educação, Ciência e Tecnologia do Rio Grande do Sul (IFRS), Porto Alegre - RS - Brasil. Professor de ensino técnico, tecnológico e médio do IFRS no campus Restinga em POA nas disciplinas da área de gestão. E-mail: educristello@ hotmail.com

RPGE- Revista on line de Política e Gestão Educacional, Araraquara, v.22, n.1, p. 336-350, jan./abr. 2018 DOI: $10.22633 /$ rpge.v22.n.1.2018.10414 
alguna forma mejorar su condición profesional con el curso en análisis y aún el 78\% eligió la modalidad EaD en función de la flexibilidad de horario y que el $80 \%$ recomendaría el curso para un amigo.

PALAVRAS-CLAVE: Egresados. Administración. EAD. Calidad.

ABSTRACT: The present study intends to know the academic profile of the undergraduate student in the course of Administration in the modality of distance learning and their perceptions of quality, through a case study in the one of a Private Higher Education Institution in the state of $R S$. The research was carried out in the group of the EaD Administration graduates of the year 2015. It is an exploratory, quantitative research, and to collect the data a questionnaire was applied through a non-probabilistic sampling for convenience and a total of 35 graduating students from 2015. The analysis of the data was done with the help of Gretl statistical software. The main results show that the majority of the students $(61 \%)$ are female, that only $2 \%$ of those surveyed do not have any form of work and considers themselves only a student, that $38 \%$ of respondents have somehow managed to improve their professional status with the course under analysis and still $78 \%$ chose the distance learning modality due to the flexibility of the schedule and that $80 \%$ would recommend the course to a friend.

KEYWORDS: Graduate. Administration. Distance learning. Quality.

\section{Introdução}

Para se diferenciarem no mercado as organizações precisam fazer algo que lhes proporcione credibilidade, oferecendo serviços que fogem do comum agregará valor tanto ao serviço quanto para ela própria.

Sendo assim a prestação de serviços educacionais precisa também se adaptar as exigências e anseios da sociedade. Conforme Viebrantz e Morosini, (2009), nestes tempos de supercomplexidade da educação superior, a necessidade da garantia de qualidade tornou-se uma das questões centrais no debate acerca da qualidade e da expansão da educação superior.

Para Santiago et al apud Viebrantz e Morosini, (2009), a qualidade da educação fornecida é igualmente importante para assegurar que graduados estejam efetivamente equipados para participar na nova economia e na sociedade com liberdade.

Como se pode observar nos conceitos acima mencionados, a importância de atender de forma adequada as expectativas do público externo, e o impacto positivo ou negativo que isso pode acarretar na qualidade dos serviços, que no caso de uma instituição de ensino pode repercutir até mesmo na permanência ou evasão do aluno em um curso de graduação, este trabalho justifica-se pelo fato de ser fonte geradora de informações, que ajudarão na tomada 
de decisões acadêmicas e pedagógicas sobre o curso em análise, no caso o curso de administração, e sobre aspectos ligados a satisfação com a modalidade de ensino escolhida.

Este trabalho tem como objetivo geral analisar o perfil do aluno egresso do curso de administração de uma Instituição de Ensino Superior privada no Rio Grande do Sul, na modalidade de ensino a distância e tem como objetivos específicos identificar as percepções de qualidade dos egressos na modalidade de ensino a distância, os objetivos atingidos com o curso, motivos para escolha do curso, motivos da escolha pela modalidade de ensino a distância. As respostas a estes objetivos visam colaborar com as decisões acadêmicas e pedagógicas, como forma de atender de forma adequada as necessidades e desejos daqueles que são os mais interessados na busca pela qualidade deste serviço, os próprios alunos ingressantes do curso de administração.

Esse estudo caracteriza-se como sendo exploratório, pois segundo Trades e Dias (2011, p. 32), este tipo de pesquisa é indicado para explorar a complexidade do fenômeno e desvendar as várias maneiras pelas quais ele se manifesta, bem como também os fatores relacionados ao seu desenvolvimento.

A população da pesquisa foi composta de 35 alunos egressos do $2^{\circ}$ semestre do ano de 2015 do curso de administração do turno da noite da IES na modalidade de ensino a distância sendo que em função do $\mathrm{n}^{\circ}$ restrito de alunos todos foram pesquisados.

Os dados foram coletados mediante a entrega de um questionário auto administrado, contendo questões fechadas a população da pesquisa, e a aplicação do instrumento deram-se no final do semestre de 2015 no mês de novembro.

Esse artigo está estruturado da seguinte forma: em um primeiro momento abordaremos os conceitos gerais referentes a educação a distância, bem como o crescimento do ensino a distância no Brasil posteriormente abordará os conceitos ligados a serviços e referenciais de qualidade ligados a educação a distância, após partimos para metodologia utilizada para realização deste trabalho, bem como os resultados da pesquisa, e logo após as considerações finais.

\section{Revisão de literatura}

\section{Educação a Distância}

Segundo Mattar e Maia (2007, p. 94) o ambiente de educação tem passado por mudanças radicais nos últimos anos e a educação a distância é um dos pilares dessas mudanças. O ambiente educacional tem se tornado cada vez mais imprevisível, pois as

RPGE- Revista on line de Política e Gestão Educacional, Araraquara, v.22, n.1, p. 336-350, jan./abr. $2018 \quad$ ISSN: 1519-9029 
novas tecnologias têm possibilitado formatos de educação antes inimagináveis, principalmente em função do uso da internet.

Para os autores mencionados acima, o aprendizado é uma das marcas da sociedade da informação e do conhecimento, e nessa nova sociedade, a educação a distância é essencial porque permite que os alunos aprendam "face a face, a distância".

Embora muitas pessoas só recentemente tenham descoberto a possibilidade de aprendizagem a distância, ela é, na verdade, uma prática tradicional, que começou por volta de 1850, em vários países da Europa. (LITTO, 2010, p. 25)

Ainda segundo o autor no caso do ensino superior, a Universidade de Londres começou programas de aprendizagem a distância em 1858, através de cursos por correspondência e teve entre seus alunos mais ilustres Mahatma Gandhi e Nelson Mandela (que estudaram Direito), além de quatro cientistas que posteriormente foram contemplados com o Prêmio Nobel.

Segundo Kenski (2007, p. 45) as novas tecnologias de comunicação (TICs), sobretudo a televisão e o computador movimentaram a educação e provocaram novas mediações entre a abordagem do professor, a compreensão do aluno e o conteúdo.

Ainda segundo a autora as tecnologias comunicativas mais utilizadas em educação não provocam ainda alterações radicais nas estruturas dos cursos, na articulação dos conteúdos e não mudam as maneiras como os professores trabalham didaticamente com seus alunos, ficando ainda muito longe de serem usadas com todas as suas possibilidades para uma melhor educação.

\section{A evolução da Educação a Distância no Brasil}

Segundo o Censo 2014 (INEP, 2014) neste ano o Brasil registrou 32.878 cursos, considerando somente cursos de graduação. Ainda segundo o mesmo censo os cursos de graduação tiveram um crescimento de $10,25 \%$ em relação ao ano de 2013. Quanto às matrículas por modalidade de ensino, os cursos de educação a distância (EaD) alcançaram $17,1 \%$ do total de matrículas no ensino superior, já a modalidade presencial tem $82,9 \%$ do total.

Outro dado que merece destaque é o aumento do número de concluintes na $\mathrm{EaD}$, que entre 2013 e 2014 cresceu 17,8\%, enquanto os cursos presenciais tiveram um aumento de 0,9\% quando comparado a 2013. Isso revela que o EAD não é só um modismo passageiro, mas uma forma de atender a reais necessidades do país, e que de alguma forma estamos 
caminhando não só para o aumento dos números, mas também, para uma análise qualitativa dos cursos ofertados.

Segundo Mandelli (2010), dados do Ministério da Educação de 2010 mostravam que um em cada cinco novos alunos de graduação no País ingressava em um curso a distância. Ou seja: cerca de $20 \%$ dos universitários já estudavam entre aulas na internet e em polos presenciais naquele ano.

\section{Qualidade nos serviços educacionais}

Segundo Kotler e Armstrong (2008, p. 68), serviço é qualquer ato ou desempenho, intangível que uma parte oferece a outra e que não resulta na posse de nada, sua execução pode ou não estar relacionado a um produto concreto.

Para maioria dos especialistas a satisfação do cliente e qualidade do serviço estão entrelaçados, o primeiro está relacionado a uma medida de curto prazo, ao passo que o segundo decorre da avaliação geral do longo prazo de um desempenho. (Hoffman; Bateson, 2008, p. 357)

Para se diferenciar no mercado as organizações precisam fazer algo que lhes proporcione credibilidade, e oferecendo serviços que fogem do comum agregará valor tanto ao serviço quanto para ela própria.

Segundo Oliveira et al (2004), a tarefa da melhoria continua da qualidade na educação superior, embora seja uma discussão bastante antiga, ainda é muito atual, e cabe ao governo, aos dirigentes das instituições de ensino superior (IES), aos docentes e discentes acompanhar o processo e contribuir para sua melhoria.

Sendo assim a prestação de serviços educacionais precisa também se adaptar as exigências e anseios da sociedade. Conforme, Viebrantz e Morosini (2009), nestes tempos de supercomplexidade da educação superior a necessidade da garantia de qualidade tornou-se uma das questões centrais no debate acerca da qualidade e da expansão da educação superior.

Conforme Libâneo, Oliveira e Toschi (2005, p. 105), as universidades precisarão se adaptar ao novo paradigma produtivo da filosofia da qualidade total aplicada ao ensino superior. As instituições devem então agregar novos valores a seus serviços, ao mesmo tempo, que redescobrem sua natureza, missão e sua identidade.

Ainda segundo os mesmos autores esta nova cultura institucional levaria as universidades a buscar constantemente a qualidade total dos serviços, bem como formar profissionais capazes de corresponder às sempre novas necessidades do mercado. 
Toda instituição deve trabalhar para obtenção de um padrão de qualidade que supere as expectativas e necessidades dos clientes, extrapolando as avaliações de caráter legal. (OLIVEIRA, 2004, p. 232)

\section{Qualidade na Educação a Distância}

O conceito de qualidade no contexto educacional implica discutir as dimensões sociais, políticas e acadêmicas, o que inevitavelmente resulta na análise das estruturas, dos processos e dos resultados decorrentes das práticas de ensino presenciais ou a distância. (ROESLER, 2011a)

Ainda segundo a autora a educação à distância, como modalidade de ensino é capaz de ampliar as possibilidades de acesso à educação, que é viabilizada a partir da incorporação das TIC - Tecnologias de Informação e Comunicação e de modelos pedagógicos e gerenciais que possibilitam sua expansão e a qualidade dos serviços educacionais.

Ainda segundo Roesler, (2011b) ao planejar uma educação a distância que se paute em referenciais de qualidade, você precisa, inevitavelmente, compreender quais as características que norteiam esta modalidade, e entre elas a autonomia de aprendizagem do estudante se constitui como uma das características centrais da $\mathrm{EaD}$, oportunizando, por um lado, que os aprendizes imprimam um ritmo de estudo de acordo com o que lhes for mais conveniente e, por outro lado, que estes avancem no seu aprendizado de acordo com o grau de maturidade, interesse e conhecimento prévio que detêm sobre determinado objeto de estudo, garantindo a autogestão do conhecimento.

A autora ainda destaca que a avaliação tem fundamental importância para o processo de ensino e sua eficácia advém da qualidade do material didático disponibilizado para os estudos da disciplina, do qual as atividades de avaliação fazem parte. Propondo estratégias de avaliação o professor possibilita ao aluno avaliar o progresso de sua aprendizagem e fazendo isso ambos terão condições de avaliar as necessidades de novas orientações para os objetos de estudos.

Após identificar o serviço educacional (educação a distância), é preciso identificar as características de qualidade que são importantes para os clientes (alunos, demais). Para garantir a satisfação dos clientes, é preciso transformar estas características em grandezas mensuráveis, que são denominadas em indicadores de desempenho. $\mathrm{O}$ desenvolvimento de um nível de qualidade se refere àquelas atividades envolvidas no desenvolvimento do serviço educacional ou do processo novo. (ROESLER, 2011c) 
Portanto podemos observar que a educação a distância, tem características exclusivas que contribuirão de forma significativa para o desempenho e para qualidade deste serviço educacional e cabe aos responsáveis entender o impacto positivo e/ou negativo que estas características trazem para o processo educacional, devendo maximizar pontos fortes e atuar em cima das fragilidades, a fim de atender e satisfazer as necessidades dos alunos, e agregar valor aos serviços prestados.

\section{Análise dos resultados}

A seguir apresentam-se os principais resultados da pesquisa junto aos alunos egressos do curso de administração da IES estudada. Para facilitar a visualização e entendimento dos resultados alcançados os mesmos foram disponibilizados em gráficos de barras como segue:

Gráfico 1: Sexo

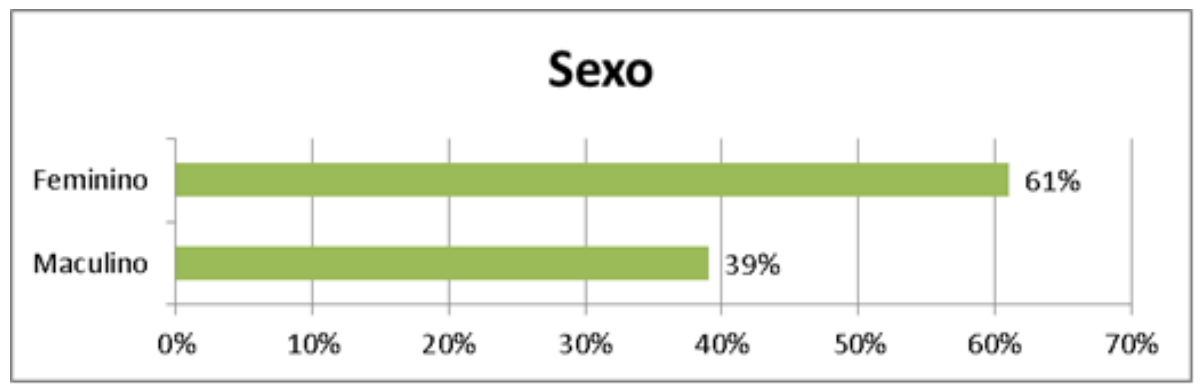

Fonte: o autor

Gráfico 2:Faixa Etária

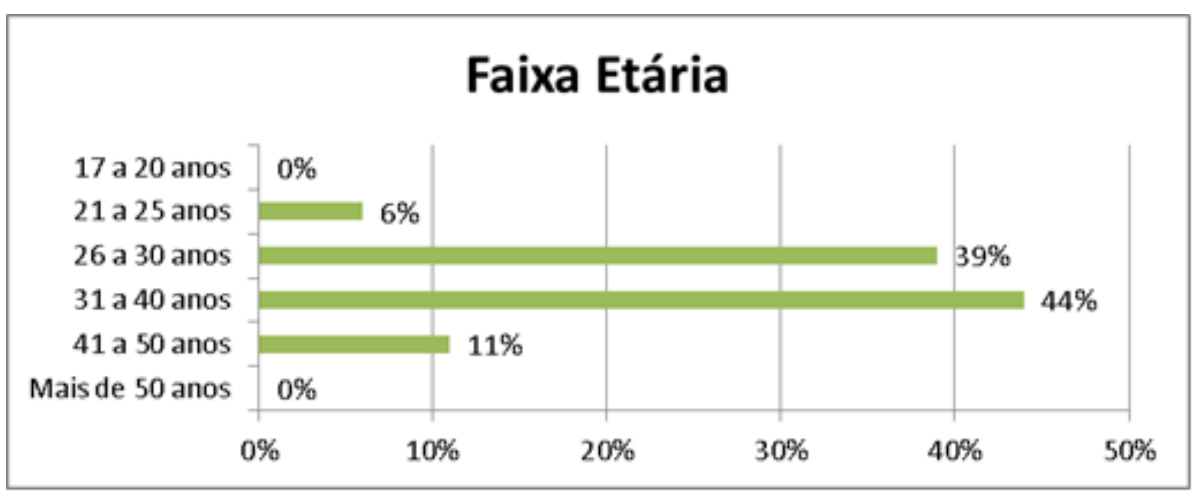

Fonte: o autor

Podemos observar nos gráficos acima a predominância do sexo feminino (61\%) entre os egressos do curso de Administração EaD, isso também comprova o aumento do $\mathrm{n}^{\mathrm{o}}$ de mulheres no mercado de trabalho e também o aumento de profissionais do sexo feminino em cargos de chefias dentro das organizações. 
Enquanto, em relação a faixa etária observamos a grande maioria $83 \%$ dos alunos encontram-se na faixa dos 26 aos 40 anos sendo que a faixa dos 31 aos 40 anos chega a $44 \%$ do total dos pesquisados, dados que são comprovados pelo último relatório do Censo do INEP (2013) que diz que os alunos do EaD tem uma faixa etária média maior do que os alunos dos cursos presenciais 31,3 anos, contra 25,8 anos respectivamente.

Gráfico 3: Renda Familiar

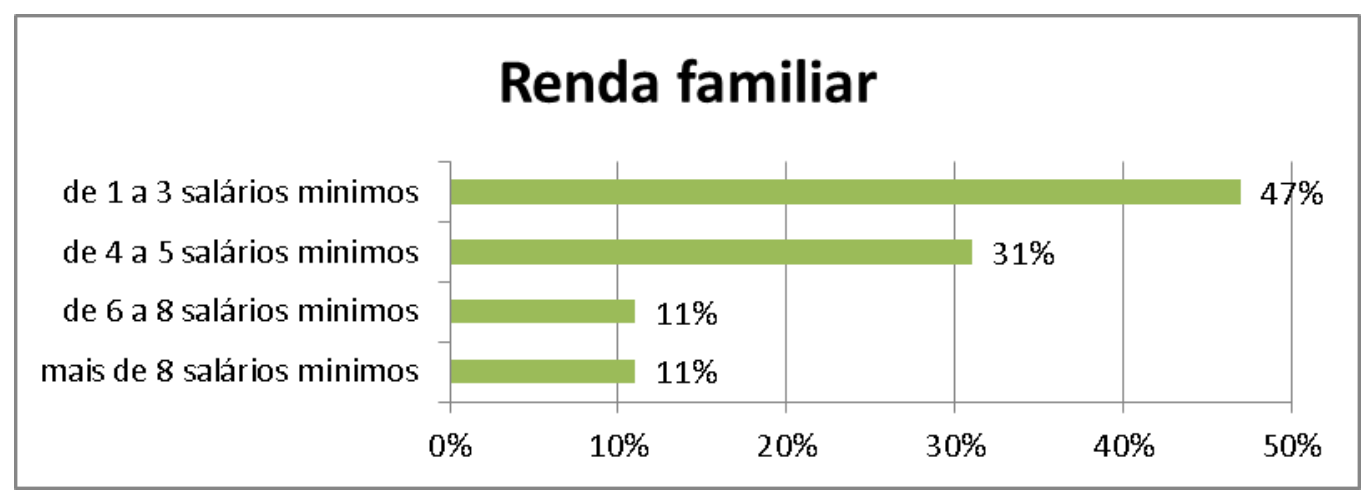

Fonte: o autor

Quando questionados sobre a renda, podemos concluir que $78 \%$ dos pesquisados tem renda familiar de até 5 salários mínimos e que mais de 53\% dos pesquisados são trabalhadores de empresas privadas, e que do total de alunos do curso, $98 \%$ tem alguma forma de trabalho e que somente $2 \%$ se considera só estudante, dados estes que também são confirmados pelo último resumo técnico do censo do INEP (2013), que diz que a maioria dos alunos de EaD são trabalhadores, que buscam uma qualificação maior, ou ainda são profissionais que estão atrás de outra graduação, não esquecendo a informação anterior de que $83 \%$ dos pesquisados estão na faixa dos 26 aos 40 anos de idade o que colabora com as informações acima mencionadas.

Gráfico 4: Ocupação atual

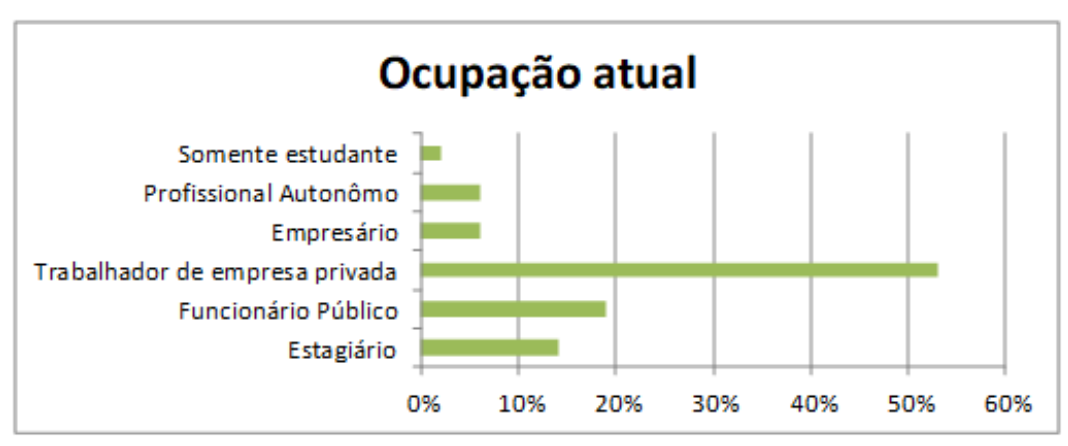

Fonte: o autor 
Em relação ao principal meio de comunicação utilizado para buscar informações, o gráfico abaixo demonstra que $78 \%$ dos pesquisados utiliza a internet com principal ferramenta na busca por informações, porém a TV, mídia mais tradicional, ainda aparece como preferida com $20 \%$ do total dos pesquisados, isso pode ser confirmado até mesmo em função da idade dos pesquisados, cujos jovens tem mais tendência para o uso de novas tecnologias e os mais velhos em modelos mais tradicionais.

Gráfico 5:Meio de comunicação utilizado

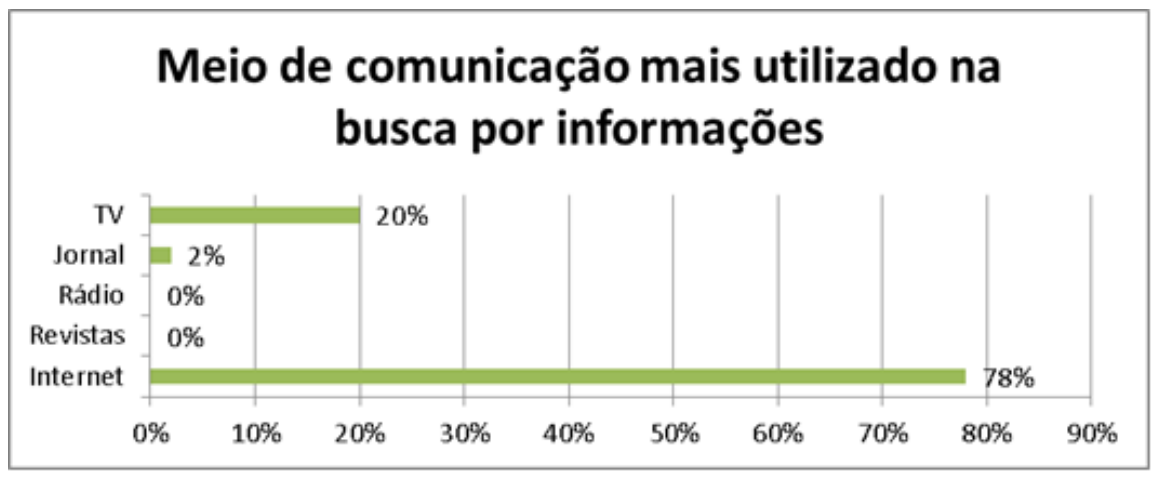

Fonte: o autor

De acordo com o gráfico a seguir, $36 \%$ dos pesquisados fizeram a opção pelo curso de administração em função da necessidade profissional, enquanto $25 \%$ buscavam algum tipo de reconhecimento e outros $28 \%$ a satisfação pessoal.

Gráfico 6: Motivação

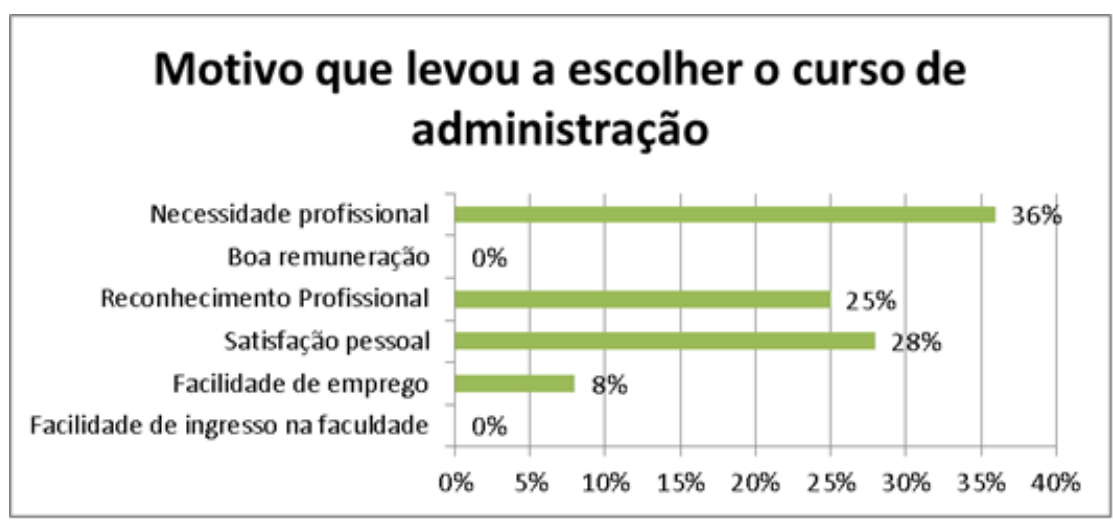

Fonte: o autor

Quando questionados qual o objetivo pessoal que conseguiram atingir com o curso, o gráfico a seguir demonstra que 50\% ainda não conseguiu atingir seu objetivo, vale lembrar que atualmente só um curso superior não é suficiente para garantir o sucesso na carreira e é preciso ter em mente a ideia de uma educação continuada, indo mais adiante na formação, através de um curso de pós-graduação por exemplo. Mas o gráfico ainda mostra que $17 \%$ dos

RPGE- Revista on line de Política e Gestão Educacional, Araraquara, v.22, n.1, p. 336-350, jan./abr. $2018 \quad$ ISSN: 1519-9029 DOI: $10.22633 /$ rpge.v22.n.1.2018.10414 
alunos egressos da Administração EaD conseguiram mudar de emprego e outros 19\% conseguiram progredir na carreira, sendo assim quase $40 \%$ dos pesquisados tiveram acréscimo em sua vida profissional fazendo um curso de administração na modalidade a distância.

Gráfico 7:Objetivos pessoais

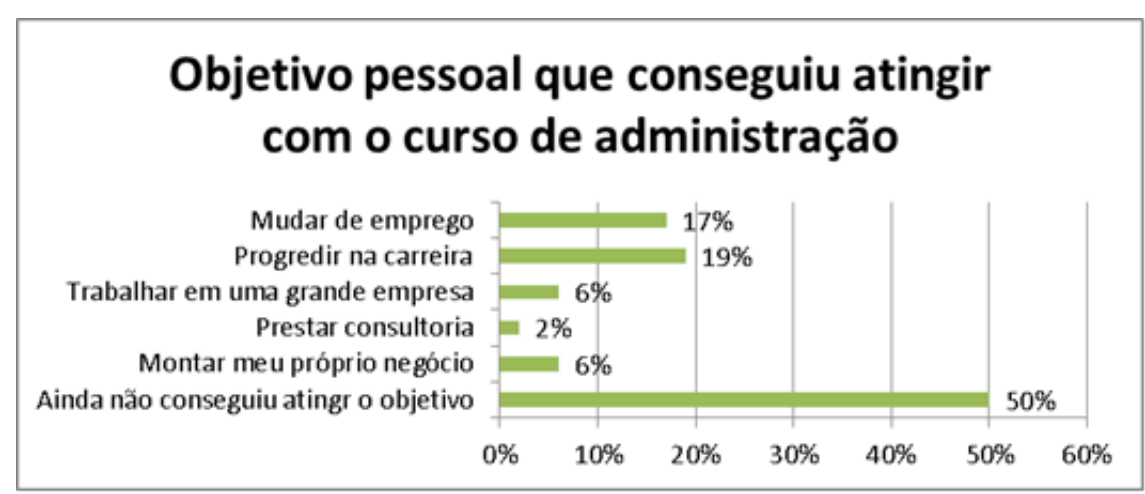

Fonte: o autor

Gráfico 8: Escolha

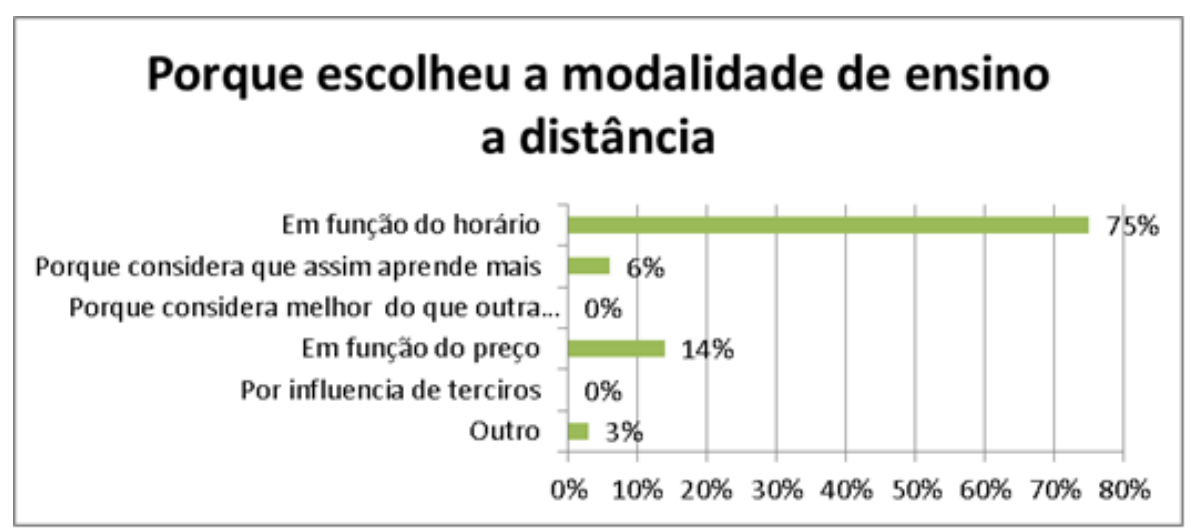

Fonte: o autor

No gráfico acima quando questionados do motivo de fazer a opção por um curso a distância, outra informação que corrobora com os censos do INEP (2010) e INEP (2013), é que $75 \%$ dos pesquisados optaram pelo curso em função da flexibilidade de horário e somente $14 \%$ disseram que fazem o curso por que é mais barato, portanto na hora da opção pela modalidade de ensino a questão preço não é a mais importante e sim a capacidade do curso atender as necessidades de tempo do aluno.

Este último gráfico demonstra que $80 \%$ dos alunos egressos do curso de administração $\mathrm{EaD}$ recomendaria o curso para um amigo. 
Gráfico 9:Recomendação

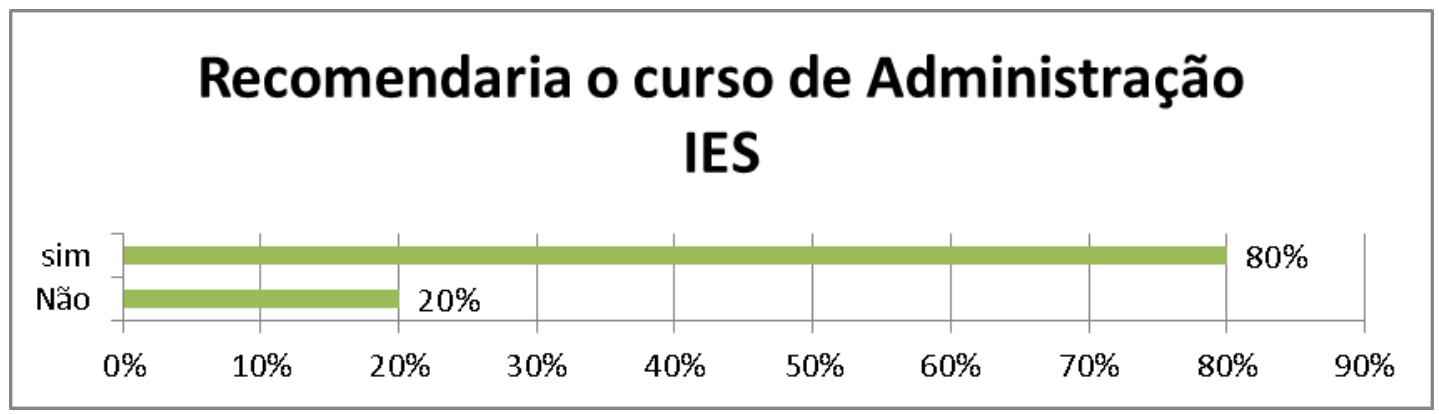

Fonte: o autor

\section{Fatores de qualidade na percepção dos alunos}

Foi proposto aos pesquisados que eles dessem notas aos vários aspectos que interferem na percepção de qualidade que eles têm do curso, para tanto foi solicitado que fossem dadas notas de 0 a 4 quando os quesitos fossem avaliados de forma negativa, e os valores de 6 a 10 quando os quesitos fossem avaliados de forma positiva. A nota 5 foi sugerida quando o quesito se encontrava em situação média, nem tanto em um estágio excessivamente ruim ou excessivamente bom.

Vale a pena ressaltar que nenhum quesito ficou abaixo da média estipulada (5), o que leva a concluir que todos os quesitos estão dentro do esperado pelo aluno, porém alguns podem ser mais bem trabalhados a fim de melhorar a percepção de qualidade no futuro, como por exemplo: $(5,56)$ facilidade de contato com o professor tutor a distância; $(5,36)$ possibilidade de comunicação com demais participantes; $(5,44)$ possibilidade de ter acesso ao material de aula; $(5,64)$ Follow up das atividades feitas e faltantes.

Já alguns quesitos aparecem com uma média superior o que faz com que as percepções de qualidade sejam maiores como por exemplo: $(6,81)$ Adequação das ementas do curso ao mercado de trabalho; $(6,58)$ quantidade de exercícios propostos; $(6,69)$ Qualificação do professores e tutores - Conhecimento do assunto; $(6,72)$ Didática do professor e tutor; $(6,53)$ Acervo geral da biblioteca.

Em termos gerais a média com o curso ficou em 6,33, demonstrando um grau de satisfação geral com o curso de Administração na modalidade a distância.

Tabela1: Percepções de qualidade na visão dos alunos egressos da IES estudada 


\begin{tabular}{|c|c|c|}
\hline Questão & Pergunta & Média/EAD \\
\hline 11 & Boa acessibilidade ao curso. & 5.25 \\
\hline 12 & Facilidade de comunicação com o professor/tutor. & 5.56 \\
\hline 13 & Possibilidade de comunicação com os demais participantes. & 5.36 \\
\hline 14 & Possibilidades de ter acesso ao material de aula /online. & 5.44 \\
\hline 15 & Mecanismos de entregas de tarefas ao professor/tutor. & 6.28 \\
\hline 16 & Disponibilidade de recursos para a realização do curso. & 6.19 \\
\hline 17 & Follow-up das atividades feitas e faltantes. & 5.64 \\
\hline 18 & $\begin{array}{l}\text { Comunicação extra-aula professor/tutor-aluno, aluno- } \\
\text { professor/tutor. }\end{array}$ & 6.33 \\
\hline 19 & Informações sobre a disciplina no início do semestre. & 6.08 \\
\hline 20 & Recursos utilizados na execução das aulas (multimídia). & 6.25 \\
\hline 21 & Cronograma das atividades. & 6.53 \\
\hline 22 & $\begin{array}{l}\text { Portal internet para ter acesso às aulas ou pesquisa quando } \\
\text { solicitado. }\end{array}$ & 5.75 \\
\hline 23 & Tempo para responder as tarefas. & 6.44 \\
\hline 24 & Forma em que os conteúdos são abordados. & 6.39 \\
\hline 25 & Ter a possibilidade de aprofundamento dos assuntos de aula. & 6.19 \\
\hline 26 & Quantidade de exercícios. & 6.58 \\
\hline 27 & Possibilidade de ter Estudo dirigido pelo professor/tutor. & 6.56 \\
\hline 28 & Clareza dos textos e assuntos abordados em aula. & 6.36 \\
\hline 29 & Qualidade das informações sobre o curso. & 6.47 \\
\hline 30 & Metodologia utilizada possibilita aprendizagem. & 6.47 \\
\hline 31 & Adequação das ementas ao mercado de trabalho. & 6.81 \\
\hline 32 & $\begin{array}{l}\text { Qualificação dos professores/tutores - Conhecimento do } \\
\text { assunto. }\end{array}$ & 6.69 \\
\hline 33 & Qualificação do professor/tutor - Didática. & 6.72 \\
\hline 34 & Biblioteca - acervos adequados. & 6.53 \\
\hline 35 & Satisfação geral com o curso? & 6.33 \\
\hline
\end{tabular}

Fonte: autor

\section{Considerações Finais}

Ao término deste estudo podemos chegar a algumas conclusões relevantes sobre a proposta de trabalho, que teve como objetivo geral analisar o perfil do aluno egresso do curso de administração de um IES privada do Rio Grande do Sul, na modalidade de ensino a distância e teve como objetivos específicos identificar as percepções de qualidade dos 
egressos na modalidade de ensino a distância, os objetivos atingidos com o curso, informações demográficas, motivos para escolha do curso, motivos da escolha pela modalidade de ensino a distância.

Podemos concluir que este estudo confirma muitas das informações contidas nos censos do INEP (2010), INEP (2013) e INEP (2014), como por exemplo o supremacia da mulher no cursos de graduação, neste trabalho as mulheres representam $61 \%$ dos egressos do curso de administração; outro dados confirmado pela pesquisa é sobre a faixa etária dos alunos $\mathrm{EaD}$, que nesta pesquisa revelou que (83\%) dos egressos estavam na faixa dos 26 aos 40 anos, sendo esta faixa maior que média de idade dos alunos de cursos presenciais que é de 25,8 anos segundo o INEP (2013).

Outro ponto relevante é que o aluno do curso a distância, é muitas vezes trabalhador que deseja melhorar na carreira, sendo assim 53\% dos pesquisados estavam nesta situação, além do motivo da escolha pela modalidade que demonstrou que $78 \%$ dos alunos egressos fizeram a opção pelo curso em função da flexibilidade de horário, que segundo os mesmos censos é o principal motivo da escolha do curso na modalidade EaD.

Quanto às percepções de qualidade dos egressos do curso de Administração na modalidade de ensino a distância, a média geral de 6,33 demonstra um grau de satisfação com o curso, porém é interessante observar aspectos que estão com médias menores a fim de buscar melhorias.

Por ora, este trabalho serviu para observar aspectos mensuráveis que interferem na percepção de qualidade do aluno e impactam diretamente a Instituição de Ensino Superior a qual pertencem em função da qualidade na prestação de seus serviços, por isso torna-se interessante o uso das informações deste estudo para tomada de decisão futura da organização, e também serve de matéria prima para outros pesquisadores que desejarem complementar este trabalho.

\section{REFERÊNCIAS}

HOFFMAN, D.; BATESON, J. E. G. Princípio de marketing de serviços: conceitos estratégias e casos. SP. Cengage learning, 2008.

HORA, D. L. Gestão Democrática na escola. Campinas: Papirus Editora, 2005.

INSTITUTO NACIONAL DE ESTUDOS E PESQUISAS EDUCACIONAIS ANISIO TEIXEIRA - INEP. Censo da Educação Superior. Ministério da Educação e Cultura. Brasil, 2010. Disponível em:

$<$ http://portal.mec.gov.br/index.php?option=com_content\&view=article\&id=17212>. Acesso em: 10 jul. 2016.

RPGE- Revista on line de Política e Gestão Educacional, Araraquara, v.22, n.1, p. 336-350, jan./abr. 2018 
INSTITUTO NACIONAL DE ESTUDOS E PESQUISAS EDUCACIONAIS ANISIO TEIXEIRA - INEP. Resumo Técnico do Censo da Educação Superior. Ministério da Educação e Cultura. Brasil, 2013. Disponível em: <http://portal.inep.gov.br/web/censo-daeducacao-superior/resumos-tecnicos>. Acesso em: 15 jun. 2016.

INSTITUTO NACIONAL DE ESTUDOS E PESQUISAS EDUCACIONAIS ANISIO TEIXEIRA - INEP. Notas estatísticas do Censo da Educação Superior. Ministério da Educação e Cultura. Brasil, 2014. Disponível em:

<http://download.inep.gov.br/educacao_superior/censo_superior/documentos/2015/notas_sob re_o_censo_da_educacao_superior_2014.pdf>. Acesso em: 12 jun. 2016.

KOTLER, P.; Armastrong, G. Princípios de marketing. 12 ed. SP: Prentice Hall, 2008.

LIBÂNEO, J. C.; OLIVEIRA, J. F.; TOSCHI, M. Educação Escolar: políticas, estrutura e organização. 2 ed. SP:Cortez, 2005.

LITTO, F. M. Aprendizagem a distância. SP. Impressa Oficial do Estado de São Paulo, 2010.

MANDELLI, M. Ensino a distância já atrai um em cada cinco novos estudantes de graduação. Disponível em: <http://www.eadbrasil.com/2010/04/>. Acesso em: 10 jul. 2016.

MORAN, J. M. Fundamentos Políticas e Legislação em EaD. Leitura Fundamental - Aula 2. - Curso de pós-graduação em Metodologia e Gestão em EaD. Faculdade Anhanguera, 2011.

MORAN, J. M. Fundamentos Políticas e Legislação em EaD. Leitura Fundamental - Aula 3. - Curso de Pós-Graduação em Metodologia e Gestão em EaD. Faculdade Anhanguera, 2011

MORAN, J. M. ABC da EaD: a educação à distância hoje. SP: Prentice Hall, 2007.

OLIVEIRA, J. O. (Org). Gestão da Qualidade: tópicos avançados. SP. Editora Thomson Learning, 2004.

ROESLER, J. Os parâmetros legais para uma educação a distância de qualidade- Leitura Fundamental - aula 1. Curso de Pós-Graduação em Metodologia e Gestão em EAD. Faculdade Anhanguera, 2011a.

ROESLER, J. Os parâmetros legais para uma educação a distância de qualidade- Leitura Fundamental - aula 2. Curso de Pós-Graduação em Metodologia e Gestão em EAD. Faculdade Anhanguera, 2011b.

ROESLER, J. Os parâmetros legais para uma educação a distância de qualidade- Leitura Fundamental - aula 3. Curso de Pós-Graduação em Metodologia e Gestão em EAD.

Faculdade Anhanguera, 2011c. 
ROESLER, J. Os parâmetros legais para uma educação a distância de qualidade- Leitura Fundamental - aula 4. Curso de Pós-Graduação em Metodologia e Gestão em EAD. Faculdade Anhanguera, 2011d.

SANTOS, C. R (Org.). Avaliação Educacional: um olhar reflexivo sobre sua prática. SP: Avercamp, 2005.

VIEIRA, A.; ALMEIDA, M, E.; ALONSO, M. Gestão educacional e tecnologia. SP: Avercamp, 2005.

VIEBRANTZ, R; MOROSINI, M. C. Qualidade e educação superior: a norma de qualidade para a aprendizagem, educação e formação: ISO/IEC 19796-1. Porto Alegre: Revista Educação v. 32, n. 3, p. 277-285, set./dez,. 2009.

\section{Como referenciar este artigo}

CRISTELLO, Eduardo. O perfil do aluno egresso no curso de Administração na modalidade de Educação a Distância e suas percepções de qualidade - Uma realidade de instituição privada do Rio Grande do Sul/Brasil. Revista on line de Política e Gestão Educacional, Araraquara, v.22, n.1, p. 336-350, jan./abr., 2018 ISSN: 1519-9029. DOI: 10.22633/rpge.v22.n.1.2018.10414

Submetido em: 02/01/2018

Aprovado em: 25/03/2018 